\title{
"SHOULD I STAY OR SHOULD I GO?": A MULTIPLE-CRITERIA GROUP DECISION-MAKING APPROACH TO SME INTERNATIONALIZATION
}

\author{
Miguel S. M. ROSÁRIO ${ }^{1}$, Fernando A. F. FERREIRA' ${ }^{2,3 \#}$, Amali ÇIPI ${ }^{4}$, \\ Guillermo O. PÉREZ-BUSTAMANTE ILANDER ${ }^{5}$, Nerija BANAITIENE ${ }^{6 *}$ \\ ${ }^{1}$ ISCTE Business School, University Institute of Lisbon, Lisbon, Portugal \\ ${ }^{2}$ ISCTE Business School, BRU-IUL, University Institute of Lisbon, Lisbon, Portugal \\ ${ }^{3}$ Fogelman College of Business and Economics, University of Memphis, Memphis, USA \\ ${ }^{4}$ University of Vlora "Ismail Qemali", Vlorë, Albania \\ ${ }^{5}$ Faculty of Economics and Business, University of Oviedo, Oviedo, Spain \\ ${ }^{6}$ Department of Construction Management and Real Estate, \\ Vilnius Gediminas Technical University, Vilnius, Lithuania
}

Received 28 January 2021; accepted 11 April 2021

\begin{abstract}
Due to domestic markets' current economic conditions, companies increasingly feel that they need to become actively involved in international trade. However, small and medium-sized enterprises (SMEs) typically face financial and intellectual constraints during internationalization processes. This means that decision makers must consider a wide range of different variables before deciding to internationalize firms. This study sought to integrate a well-established problem structuring method (i.e., cognitive mapping) and a multiple-criteria decision analysis (MCDA) technique (i.e., Decision EXpert (DEX)) in order to develop a decision model suitable for the identification and assessment of variables influencing SME internationalization capability. Using data collected during face-to-face meetings with a panel of experts (i.e., SME entrepreneurs and chief executive officers (CEOs)), a constructivist method of evaluating SME internationalization capability was created and tested using real data. The results confirm that the dual methodology adopted facilitates the development of a robust evaluation model that can improve decisionmaking processes in the context in question. Specifically, the proposed model identifies product features as the most important factor in SME capability for successful internationalization. In addition, internal factors are significantly more relevant than external factors. The integrated use of cognitive mapping and DEX provides decision makers with a well-informed perspective on SME internationalization capability. We know of no prior research reporting the use of these two methodologies in the SME internationalization context.
\end{abstract}

Keywords: cognitive maps, Decision EXpert (DEX), international entrepreneurship, internationalization process, small and medium-sized enterprises (SMEs).

JEL Classification: C44, C45, M10.

*Corresponding author. E-mail: nerija.banaitiene@vilniustech.lt

\#Corresponding author. E-mail: fernando.alberto.ferreira@iscte.pt

Copyright @ 2021 The Author(s). Published by Vilnius Gediminas Technical University

This is an Open Access article distributed under the terms of the Creative Commons Attribution License (http://creativecommons. org/licenses/by/4.0/), which permits unrestricted use, distribution, and reproduction in any medium, provided the original author and source are credited. 


\section{Introduction}

Due to the emergence of new technologies and increased globalization, companies much more often need to look for new markets abroad. According to Kubíčková et al. (2014, p. 320), "although not all [small and medium-sized companies (SMEs)] [...] operate in foreign markets, they all need to realize that due to [...] ongoing globalization [...] international competition is inevitable even in [...] domestic markets. This is because SMEs are no longer protected from foreign competition in their domestic markets. Thus, companies that are only present in their domestic market will gradually be pressured into internationalization either by new companies' entry or their competitors' expansion into new markets". In addition, the 2008 financial crisis had a significant impact on the consumption and purchasing power of populations worldwide (Çipi et al., 2014a; Greenbaum et al., 2015; Castela et al., 2018), which means many companies cannot survive based on domestic markets alone.

Through international trade, SMEs tend to acquire additional capabilities, strengthen their competitive and financial position, achieve new levels of innovation, and increase revenues, which benefits the economies of these firms' home countries (Çipi et al., 2014b; Kubíčková et al., 2014; Gonçalves et al., 2019). These factors have motivated many SMEs to become more competitive through their involvement in international markets.

Despite SMEs' pressing need for internationalization, the processes involved are by their nature expensive, and SMEs typically have scarce resources (Ju et al., 2020; Simões et al., 2020). These companies' internationalization is accompanied by the necessity of a rapid return on investment and a lack of the required relationships with foreign partners, which impairs SMEs' involvement in international markets (Kubíčková et al., 2014). SMEs are also usually managed by families or small groups of individuals with limited knowledge of internationalization but who still make decisions about their company's development (Kubíčková et al., 2014; Pérez-Bustamante Ilander et al., 2016; Gonçalves et al., 2019). Thus, due to the growing need for companies to become involved in international markets and the difficulty of doing so, mechanisms need to be created that support decision-making processes during SME internationalization. This need becomes even more evident if researchers take into account that studies in this field are still limited.

The present study's main objective is to develop a multi-criteria evaluation model to be used in assessments of SME internationalization capability. This model is generated by a combination of cognitive mapping techniques and the Decision EXpert (DEX) method. The proposed model allows decision makers to confirm if their firms are ready to internationalize and to identify which factors are facilitating and/or conditioning these companies' internationalization processes. Specifically, this research has the following objectives: (1) to produce results as close as possible to reality through an exhaustive process of identifying evaluation criteria and the objective and subjective aspects that need to be included; and (2) to estimate the level of each aggregate attribute's importance in order to clarify which attributes have the greatest impact on SME internationalization capability. To achieve these objectives, other intermediate goals have to be met. The first is to set up a panel of internationalization professionals willing to participate in face-to-face sessions and collaborate in the evaluation system's development. The second goal is to apply cognitive mapping techniques in order to identify and select the evaluation criteria to be included in the system for assessing SME 
internationalization capability. The last goal is to implement the DEX technique in order to define the decision rules for aggregating partial evaluations of the SMEs assessed and for providing overall evaluations for these firms. We found no previous study using this dual methodology in this research context, allowing our proposal to add to the extant literature of SME internationalization, international entrepreneurship and operational research.

The rest of this paper is organized as follows. Section 1 provides an overview of the extant literature on SME internationalization. Section 2 presents fundamental aspects of cognitive mapping and the DEX approach, highlighting the reasons why they were selected. Section 3 presents and discusses the results obtained with a real-life application of the framework developed. Finally, the last section presents the study's contributions and limitations and lays out a roadmap for future research.

\section{Prior work and research gap}

The 2008 financial crisis has proven over time to be one of the most important socioeconomic events of this millennium. This crisis has affected the financial stability of organizations, countries, and populations worldwide (Çipi et al., 2014b; Ferreira et al., 2017a; Oliveira et al., 2017; Grillo et al., 2018). The crisis sent nations and their trade activities into a vicious recessionary cycle, forcing governments to bail out many financial institutions and resulting in a contraction in loans and investment and sharp declines in financial market prices. Populations around the globe have experienced reduced consumption levels and purchasing power (Greenbaum et al., 2015; Carlucci et al., 2018).

Although the crisis started in the United States (US), the effects quickly spread to other countries, leaving visible long-lasting marks and making economic recovery slow and prolonged. With the onset of the US financial crisis in 2007 and its spread to the rest of the world, the global economy went into a recession so deep that recovery has taken many years. The disappearance of immense financial wealth immediately after the crisis had consequences for the real economy and undermined populations, companies, and even countries' sustainability (Goodwin et al., 2014; Carlucci et al., 2018). As individuals had less economic wealth, they were less willing to spend money. According to Mian et al. (2013), domestic consumption generally decreased, which further aggravated companies' financial situation and forced them to make more employees redundant, thereby beginning a vicious circle of recession (Goodwin et al., 2014).

The financial crisis's impacts on the world economy were devastating. Overall, gross domestic product (GDP) decreased around the globe by $2 \%$ in 2009, and between 50 million and 100 million people lived in extreme poverty (Goodwin et al., 2014). However, the economic landscape has changed recently, and SMEs currently are seeking to become more competitive through either their domestic market or involvement in international trade. Figure 1 shows the evolution of some indicators related to European SMEs.

Dubravska and Sira (2015, p. 1210) state that "international trade is the exchange of commodities, products, services and capital between people and companies in different countries". Many factors can influence the growth of international trade, such as exchange rates, businesses' competitiveness, customs, globalization, trade agreements, language, and cultural di- 


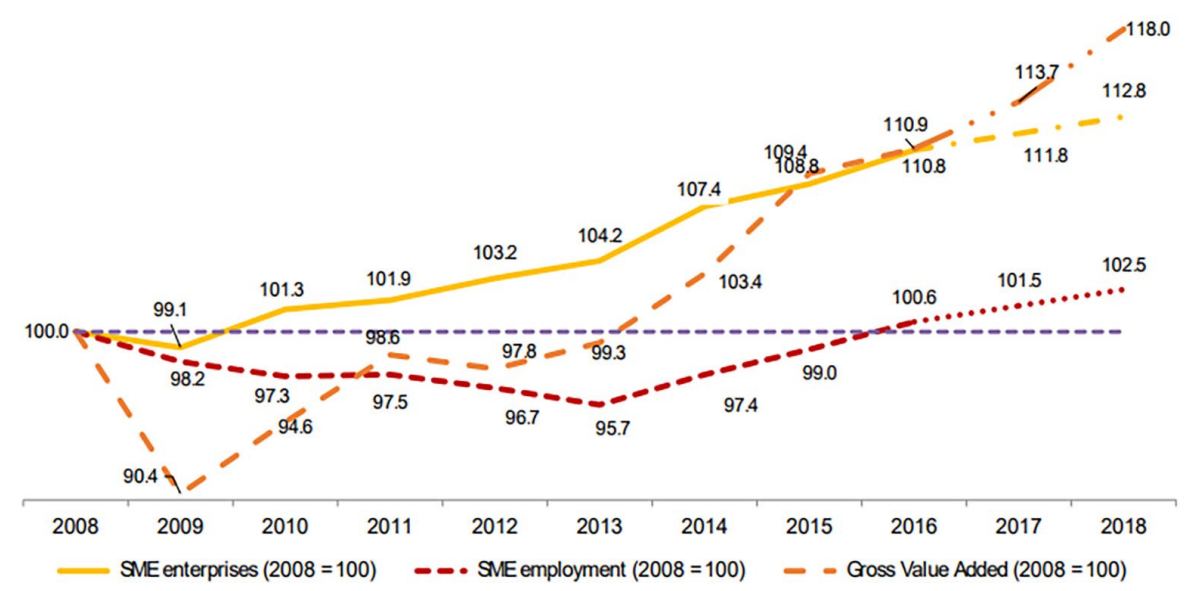

Figure 1. Recovery of European SMEs since financial crisis (source: European Commission, 2017b)

versity (Czinkota \& Ronkainen, 2012; Gonçalves et al., 2019). Through companies' involvement in international trade, they gain access to new business opportunities arising both from firms' involvement in foreign markets and from interactions with foreign consumers (Surugiu \& Surugiu, 2015).

Strong incentives exist for SMEs to increase their exposure to international markets. In the coming years, an estimated $90 \%$ of global growth will be generated outside the European Union, and, by 2030, 60\% of the world's GDP will be represented by emerging and developing markets (European Commission, 2017a). A Eurobarometer survey conducted in 2015 (see European Commission, 2017a) found that, in the previous three years, about half of European SMEs had been involved in international trade. However, for companies to become involved in international trade, they have to consider initiating internationalization processes.

Internationalization is an ambiguous concept defined in the literature according to the purposes served (Barney, 1991). For example, Welch and Luostarinen (1988, p. 36) define internationalization as the "process of increasing involvement in international operations". Dutot et al. (2014, p. 674) argue that "the internationalization of a firm is the outward movement of its operations and the process of mobilization, accumulation, and development of a specific set of resources in order to achieve greater performance". Notably, both definitions consider internationalization to be a process that implies an increased involvement of companies in international markets. Calof and Beamish (1995, p. 116) similarly define internationalization as "the process of adapting firms' operations (strategy, structure, resources, etc.) to international environments".

The literature on internationalization also emphasizes the importance of decision makers' attitudes toward internationalization (cf. Oviatt \& McDougall, 1994; Gonçalves et al., 2019), as well as these individuals' ability to identify, evaluate, and exploit business opportunities in international markets (e.g., Oviatt \& McDougall, 2005; Castela et al., 2018). Child and Hsieh (2014, p. 598), nonetheless, suggest that "the approach to decision-making found in SMEs may differ from the goal-driven and rational decision-making commonly associated with large firms". A relevant factor regarding this difference is that SMEs tend to be led by individuals (Oviatt \& McDougall, 1994; Grillo et al., 2018), so strategic decisions are quite likely influ- 
enced by personal characteristics, opportunistic behaviors, and emotions rather than rational opinions (Chandra \& Styles, 2009; Rita et al., 2018). Another relevant factor in terms of the aforementioned difference is scarcity of information (Evers \& O'Gorman, 2011). Since SMEs encounter this problem during internationalization processes, numerous studies have sought to help decision makers to make more informed and rational decisions. Different methods, techniques, and evaluation tools have been used to obtain useful and realistic results. Table 1 summarizes some of the research carried out in this area, including each study's contributions and limitations.

The studies in Table 1 applied different methodological approaches. For instance, Kunday and Sengüler (2015) used a hierarchical regression model, Dutot et al. (2014) used DSA, Pangarkar (2008) and Hollender et al. (2017) used multiple regression models, and Cerrato et al. (2016) conducted clusters analysis to test the results of various types of internationalization strategies. Some authors also chose to use other methods. These researchers include Dominguez and Mayrhofer (2017), who applied a qualitative research method based on a case study, and Yener et al. (2014), who carried out an ethnographic study to understand in detail the decisions and adversities that companies face during internationalization.

The present review of the literature further verified that some scholars have stopped short of evaluating the full spectrum of key topics in internationalization processes and instead have focused on each case's specific dimensions. For example, Dutot et al. (2014) concentrated on technology's influence on these processes, while Hollender et al. (2017) analyzed only various input methods' effects on internationalization. In addition, the lack of information on how each study's variables were defined suggests that they were identified based on each author's interpretation, which increases the possibility of biased results. Finally, most studies have been carried out within specific geographical and temporal contexts that limit the results' scope and quality, as well as their applicability to real business contexts.

Although each methodological approach has its advantages and disadvantages, certain limitations can be identified as being present across the different methods applied. First, the existing approaches have failed in the way decision criteria are defined and integrated into the respective models. Many factors can influence the choice and definition of decision criteria, such as the researchers' characteristics or statistical data's availability. Thus, using methods that limit bias in definitions of decision criteria could improve the quality of studies' results and their applicability to real contexts. Second, the subjective components that influence internationalization processes have not, in general, been given sufficient weight. For example, Pangarkar (2008), Dutot et al. (2014), Kunday and Sengüler (2015), Cerrato et al. (2016), and Hollender et al.s (2017) quantitative research did not include subjective aspects in models, so the results only reflect some of the decision problem's dimensions. The qualitative studies conducted by Yener et al. (2014) and Dominguez and Mayrhofer (2017) identified subjective aspects, but the cited authors did not quantify them.

Overall, the current literature review verified three main methodological limitations: (1) methods of identifying evaluation criteria; (2) methods of calculating the evaluation criteria's level of importance; and (3) idiosyncratic identification of objective evaluation criteria. Thus, despite prior studies' undeniable contributions, none of them has been free of limitations. The present research proposed the integrated use of cognitive mapping and the DEX method in this research context to address some of these methodological limitations. 
Table 1. Methods for assessing SME internationalization capability: contributions and limitations

\begin{tabular}{|c|c|c|c|}
\hline Author & Method & Contributions & Limitations \\
\hline $\begin{array}{l}\text { Pangarkar } \\
(2008)\end{array}$ & $\begin{array}{l}\text { Multiple } \\
\text { regression } \\
\text { model }\end{array}$ & $\begin{array}{l}\text { - Evaluated the impact } \\
\text { of SMEs' degree of } \\
\text { internationalization }\end{array}$ & $\begin{array}{l}\text { - Omitted variables that may } \\
\text { influence internationalization } \\
\text { decisions } \\
\text { - Based sample only on SMEs in } \\
\text { Singapore }\end{array}$ \\
\hline $\begin{array}{l}\text { Dutot et al. } \\
(2014)\end{array}$ & $\begin{array}{l}\text { Deviation } \\
\text { Score Analysis } \\
\text { (DSA) }\end{array}$ & $\begin{array}{l}\text { - Clarified the influence } \\
\text { of information and } \\
\text { information technologies } \\
\text { on internationalization } \\
\text { performance }\end{array}$ & $\begin{array}{l}\text { - Based sample only on } \\
\text { Canadian SMEs } \\
\text { - Omitted variables that may } \\
\text { influence internationalization } \\
\text { decisions }\end{array}$ \\
\hline $\begin{array}{l}\text { Yener et al. } \\
\text { (2014) }\end{array}$ & $\begin{array}{l}\text { Ethnographic } \\
\text { study }\end{array}$ & $\begin{array}{l}\text { - Identified in detail adversities } \\
\text { that companies face during } \\
\text { internationalization }\end{array}$ & $\begin{array}{l}\text { - Limited sample to a single } \\
\text { Turkish SME }\end{array}$ \\
\hline $\begin{array}{l}\text { Kunday and } \\
\text { Sengüler } \\
(2015)\end{array}$ & $\begin{array}{l}\text { Hierarchical } \\
\text { regression } \\
\text { model }\end{array}$ & $\begin{array}{l}\text { - Evaluated the moderating } \\
\text { effect of the reasons for } \\
\text { starting businesses on } \\
\text { the relationship between } \\
\text { independent variables and } \\
\text { export intensity }\end{array}$ & $\begin{array}{l}\text { - Omitted variables that may } \\
\text { influence internationalization } \\
\text { decisions } \\
\text { - Only used correlation analysis, } \\
\text { so weights not established }\end{array}$ \\
\hline $\begin{array}{l}\text { Cerrato et al. } \\
\text { (2016) }\end{array}$ & $\begin{array}{l}\text { Cluster } \\
\text { analysis }\end{array}$ & $\begin{array}{l}\text { - Identified four archetypes } \\
\text { (i.e., marketer, investor, } \\
\text { networker, and weak } \\
\text { internationalizer) in } \\
\text { internationalization processes }\end{array}$ & $\begin{array}{l}\text { - Failed to include certain } \\
\text { variables that may influence } \\
\text { internationalization decisions } \\
\text { - Based sample only on Italian } \\
\text { SMEs }\end{array}$ \\
\hline $\begin{array}{l}\text { Dominguez } \\
\text { and Mayrhofer } \\
(2017)\end{array}$ & Case study & $\begin{array}{l}\text { - Defined SMEs' different } \\
\text { phases of internationalization } \\
\text { through longitudinal analysis } \\
\text { - Identified internal and } \\
\text { external factors that influence } \\
\text { internationalization and } \\
\text { cause phase changes }\end{array}$ & $\begin{array}{l}\text { - Based sample only on French } \\
\text { SMEs } \\
\text { - Produced results specific to } \\
\text { companies' situation, so not } \\
\text { generalized }\end{array}$ \\
\hline $\begin{array}{l}\text { Hollender } \\
\text { et al. (2017) }\end{array}$ & $\begin{array}{l}\text { Multiple } \\
\text { regression } \\
\text { model }\end{array}$ & $\begin{array}{l}\text { - Evaluated the impact of the } \\
\text { different methods of entry } \\
\text { into international markets } \\
\text { on internationalization } \\
\text { performance }\end{array}$ & $\begin{array}{l}\text { - Omitted variables that may } \\
\text { influence internationalization } \\
\text { decisions } \\
\text { - Based sample only on } \\
\text { Canadian SMEs }\end{array}$ \\
\hline
\end{tabular}

\section{Methodological background}

\subsection{Cognitive/causal mapping}

Cognitive mapping is a well-established problem structuring method. According to Eden (2004, p. 673), "a cognitive map is the representation of thinking about a problem that follows from the process of mapping". These maps are used to structure and organize different decision makers' options, allowing them to achieve their objectives based on their companies' specific characteristics. In addition, cognitive maps facilitate the management of cause-and-effect 
relationships between variables in complex, uncertain environments (Ackermann \& Eden, 2001; Rita et al., 2018). Castela et al. (2018) and Milici (2021) report that these maps help decision makers move from a feeling of discomfort or dissatisfaction toward the ability to define decision problems more clearly. A structured view of problems also facilitates dialogue and discussion among decision makers, thereby encouraging knowledge sharing, generating ideas, and creating models that reflect all the stakeholders' individual opinions.

Eden (2004) suggests that cognitive maps need to be organized into a hierarchical structure composed of three levels: (1) objectives at the top; (2) strategic issues in the middle; and (3) possible actions that address key issues at the bottom. However, two different approaches can be potentially adopted when structuring cognitive maps. The first is a top-down approach, in which decision makers begin by exploring the highest hierarchical level containing the main objectives. The second is a bottom-up approach, in which the lower hierarchical levels are explored first since these are where the actions required to achieve the desired objectives are located (Belton \& Stewart, 2002). Figure 2 provides an example of a cognitive map.

As shown in Figure 2, cognitive maps indicate the cause-and-effect relationships between the various criteria with arrows, whose direction implies the expected causality (Eden, 2004; Eden \& Ackermann, 2004; Filipe et al., 2015; Jalali et al., 2016; Marques et al., 2018). The arrows can depict positive (+) or negative (-) cause-and-effect relationships (Eden \& Ackermann, 2001; Ferreira et al., 2017b; Ribeiro et al., 2017). According to Montibeller and Belton (2006, p. 780), "a positive sign indicates a positive perceived causal connection, whereby an increase in a cause generates an increase in the linked effect [... while] a negative sign denotes a negative connection, whereby an increase in the cause leads to an increase in the opposite pole of the linked effect".

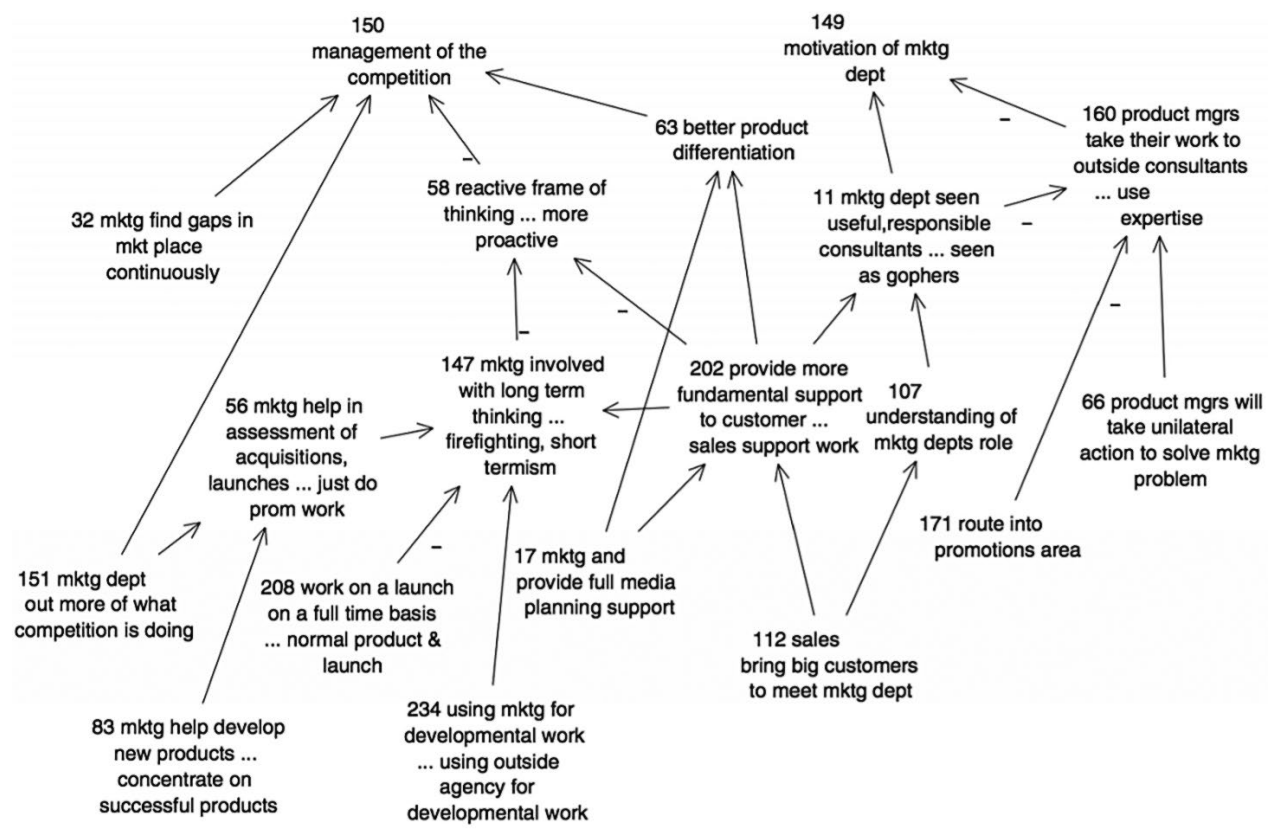

Figure 2. Partial example of a cognitive map (source: Eden, 2004, p. 675) 
Although this technique is not free of limitations (cf. Ferreira, 2016), researchers have found evidence that cognitive mapping supports decision-making processes. The method is effective primarily because it facilitates a better understanding of decision situations and contributes to reducing the number of criteria omitted from the decision-making framework.

\subsection{DEX}

The DEX method was developed over 30 years ago by Bohanec, who was inspired by Efstathiou and Rajkovičss (1979) studies. It is a qualitative tool used to support decision making that combines multicriteria evaluation techniques with expert systems. Bohanec (1991, p. 1) states that "DEX is an expert system shell for multi-attribute decision making. Its main purpose is to support the decision maker in solving complex multi-attribute decisions".

The method has been applied to solve real problems in various sectors, including, among others, health (Bohanec et al., 2000a), project evaluations (Bohanec et al., 1995), real estate (Bohanec et al., 2001), sports (Bohanec et al., 2000b), public administration, agronomy, tourism, finance, and traffic control. Bohanec et al. (2013) report that the DEX method has also made important contributions in studies related to artificial intelligence, which is considered one of the most important scientific advances in recent decades. The methodology uses the DEXi software (Bohanec, 2014), and facilitates the development of qualitative decision models with multiple criteria and the evaluation of options in an interactive way (Ferreira et al., 2016).

To analyze decision problems, the DEX method can be used to develop qualitative models with diverse criteria in order to evaluate alternative solutions to decision problems (Bohanec et al., 2013; Grillo et al., 2018). These models are based on principles that are intentionally delineated in a simplified way, so the models are formulated through the decomposition of problems into increasingly complex sub-problems. According to Bohanec et al. (2013), DEX models incorporate four major elements of which the first is attributes. These attributes represent the basic characteristics of each decision alternative. The second major element is attribute scales, which are qualitative and generally organized in order of preference, while the third is an attribute hierarchy that represents the decomposition of the decision problem and the relationships between attributes. The last element is decision rules that constitute the guidelines for relationships between attributes.

Conceptually, the DEX method consists of a combination of multicriteria evaluation techniques with expert systems (Foltin \& Smith, 1994; Bohanec et al., 2013; Grillo et al., 2018). Expert systems are included to automate the decision-making process by replicating human reasoning and behavior. The method thus introduces concepts such as "qualitative (symbolic, linguistic) variables, if-then rules, dealing with uncertainty, [... a strong] emphasis on the transparency of models and explanation of evaluation results" (Bohanec et al., 2013, p. 51). In addition, DEX focuses on presenting models' results so that they are understandable to the decision makers.

When the DEX method is applied to practical problems, decision-making processes consist of executing two fundamental steps: (1) constructing the knowledge base; and (2) evaluating and analyzing options. The first stage focuses on knowledge related to the decision problem, which is obtained through the decision makers' perspectives and experience. The 
set of tools applied are capable of dealing with "imprecision, uncertainty, and qualitative (non-numeric) nature of the expert [s'] knowledge" (Bohanec \& Rajkovič, 1990, p. 147). Specifically, the knowledge base developed consists of an attribute tree and a utility function. The latter defines the utility value of the attributes previously defined. The attribute tree represents the decision problem's structure based on the attributes' interdependence, in which higher level attributes (e.g., X4 in Figure 3) depend on lower level attributes (e.g., X5 and X6 in Figure 3). The attributes in the bottom level are termed "basic" attributes,

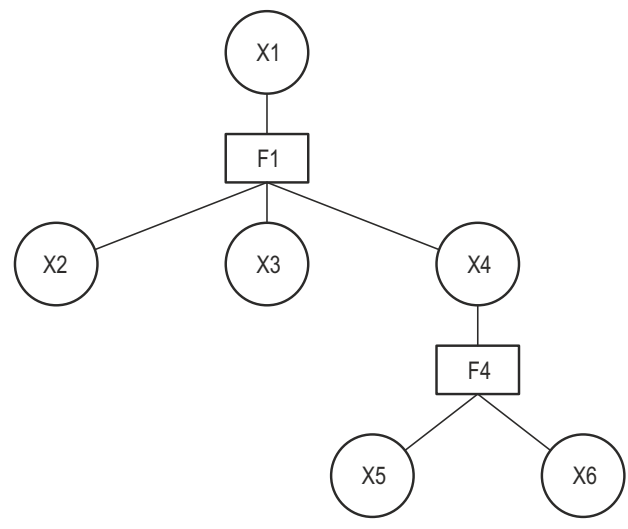

Figure 3. Example of attribute tree and utility function (source: adapted from Bohanec and Rajkovič, 1990, p. 149) while the other attributes are called "aggregate" attributes, while their value is obtained through utility functions (Bohanec \& Rajkovič, 1990). According to Bohanec and Rajkovič (1990), the most important aggregate attribute is placed at the highest level, which should represent the total utility of all attributes.

The process's second stage involves evaluating and analyzing options, which can occur as soon as the knowledge base is defined. Bohanec and Rajkovič (1990) state that this stage may consist of one or more of four activities. The first is an interactive inspection of results in which the values attributed to aggregate attributes are verified. The second activity is the evaluation's explanation, which clarifies how each aggregate attribute value was obtained. The third is what-if analysis, in which the basic attributes' values are changed and the results obtained are compared with the original results. The last activity is an explanation of the options obtained, which defines and explains the options that translate into the best results. After this clarification of the steps within the DEX method's evaluation process and the basic concepts inherent to its application, the advantages and limitations of applying this method need to be discussed next.

In terms of advantages, perhaps the most evident is the simplicity of applying DEX. The $D E X i$ software was designed to enhance its interactivity and user-friendliness, which has facilitated its adoption as a study tool in various schools and universities (Bohanec et al., 2013; Grillo et al., 2018). According to Bohanec et al. (2013, p. 50), "in spite of its simplicity, DEXi turned out to be extremely useful for most difficult decision-making tasks".

The inclusion of qualitative criteria is another feature of this method. Although traditional multiple-criteria decision analysis (MCDA) methodologies are based on variable weights used to define attributes' importance, "the partial transformation between attribute weights and decision rules is possible in both ways" (Bohanec et al., 2013, p. 52). A further relevant feature is that the DEX method combines multicriteria evaluation techniques with expert systems, which allows decision-making processes to be automated by replicating human specialists' behavior. Expert systems also allow the decisions based on the model developed to be displayed in the users' perceived language. Bohanec and Rajkovič (1990) suggest that expert 
systems provide advantages regarding: (1) the verification and acquisition of knowledge; (2) explanation of the decisions obtained; (3) analysis of various options; and (4) a qualitative or soft use of knowledge.

In addition, one of the DEX method's principles that constitutes an advantage over other techniques is that "the user is always right" (Bohanec et al., 2013, p. 51). Based on this principle, DEX gives preference to the information provided by decision makers so that "any decision rule, even if inconsistent, is taken literally and never modified by DEX. In case of [an] inconsistency, the user is given a warning" (Bohanec et al., 2013, p. 51). Finally, the exchange of knowledge and experience among decision makers is fundamental to enhancing the quality of the models and results obtained.

Regarding the DEX method's limitations, Bohanec et al. (2013, p. 53) point out that "really difficult decision problems require [a] more powerful methodology and more advanced software". For this reason, Trdin and Bohanec (2018) have sought to develop the method in three ways that, to date, are still subject to limitations. These are: (1) the introduction of numerical attributes; (2) aggregation of values using fuzzy probabilistic distributions; and (3) introduction of relational models. Trdin and Bohanec (2012) also plan to develop other aspects to provide more support for hierarchical analysis by using acyclic graphs instead of attribute trees and to introduce general aggregation functions.

The present study weighed the advantages and disadvantages of the DEX method, examined the specificities of the decision problem in question, and compared them to other MCDA techniques. DEX was selected because it fits well with the process of evaluating SME internationalization capability (Trdin \& Bohanec, 2012).

\section{Application and results}

This research sought to integrate cognitive mapping and DEX in order to assess SME capability for successful internationalization initiatives. Bana e Costa et al. (2002, p. 227) suggest that "a decision-making group of 5-7 experts and other key players" usually guarantees this kind of study will proceed well. Thus, the current research relied on a panel of experts composed of five professionals (i.e., SME managers and entrepreneurs), who have years of experience and access to different sources of knowledge about SME internationalization.

Although this expert panel was small, its size followed the recommendations for processoriented studies that put "less emphasis on outputs per se and more focus on process" (Bell \& Morse, 2013, p. 962). Methodologically, this means that the procedures followed in the present study, if correctly adjusted, can be replicated in other contexts or with different decision makers (for further discussion, see Ackermann and Eden (2001), Belton and Stewart (2002), and Ferreira et al. (2017a)). Two group sessions, with an average duration of 4 hours, were guided by 2 experienced facilitators (i.e., 2 of the authors of this study), who coordinated the negotiation process and guided the panel members during the application of the techniques. The first session covered the structuring phase. 


\subsection{Structuring phase: group cognitive map and value tree}

The initial group session started with a kickoff presentation of the objectives and methodologies. Next, cognitive mapping techniques were applied by using the strategic options development and analysis (SODA) approach, developed by Ackermann and Eden (2001). To this end, the facilitators asked the following trigger question: "Based on your values and professional experience, what characteristics and factors influence SME internationalization processes?". The question served as the starting point for a negotiation process in which the participants shared their perspectives and experiences in order to identify relevant criteria for assessing SME internationalization capability.

This step was facilitated by the "post-its technique" (Ackermann \& Eden, 2001), which encouraged the participants to write down concepts verbalized in response to the trigger question, and these notes were placed on the surface of a table. The participants then analyzed and debated each criterion, and, whenever necessary, new criteria were added or eliminated. After the criteria were accepted by the entire group, the experts organized the criteria into clusters of closely related concepts.

In the last stage of the first meeting, each cluster was carefully reviewed, and the panel members' discussion focused on establishing hierarchies among the evaluation criteria. Specifically, the panel members were asked to analyze each cluster internally and organize the decision criteria according to their relative importance. That is, the most important criteria were placed at the top of the respective cluster and the least important at the bottom (Ferreira et al., 2016; Correia et al., 2020). Based on the results of this exercise, a collective cognitive/ causal map was constructed using the Decision Explorer software (http://www.banxia.com), which facilitated the development of a holistic understanding of the decision problem under study (i.e., assessment of SME internationalization capability). Figure 4 presents the final version of the collective cognitive map developed, which was validated by the decision makers through discussion and negotiation.

After the collective map's validation, Keeney's (1992) methodological guidelines for this type of research were followed. The participants analyzed the map's cognitive branches and selected the criteria that they considered fundamental points of view (FPsV), thereby developing a tree of FPsV (or "value tree", as commonly labeled in the literature (cf. Ferreira et al., 2015)). Figure 5 shows the tree generated for SME capability for internationalization, which was collectively analyzed and approved by the group.

The panel of decision makers thus considered that SME internationalization capability depends on the following factors. Internal factors comprise the companies' internal characteristics. These include human capital, which covers the firms' human capital characteristics, as well as how human capital is managed. This factor is in turn made up of human resources, which include the companies' human resources characteristics and conditions (e.g., worker productivity, social support for workers, and corporate culture). Another human capital factor is leadership, which comprises the firm leaders' characteristics (e.g., emotional intelligence, target country knowledge, and adaptability). Product, in broad sense, is the second internal factor, which encompasses company products' characteristics (e.g., quality, price, type, and image). The last internal factor is other resources, including the organizations' other available internal resources (e.g., intangible assets, resources and equipment, website, and logistics). 


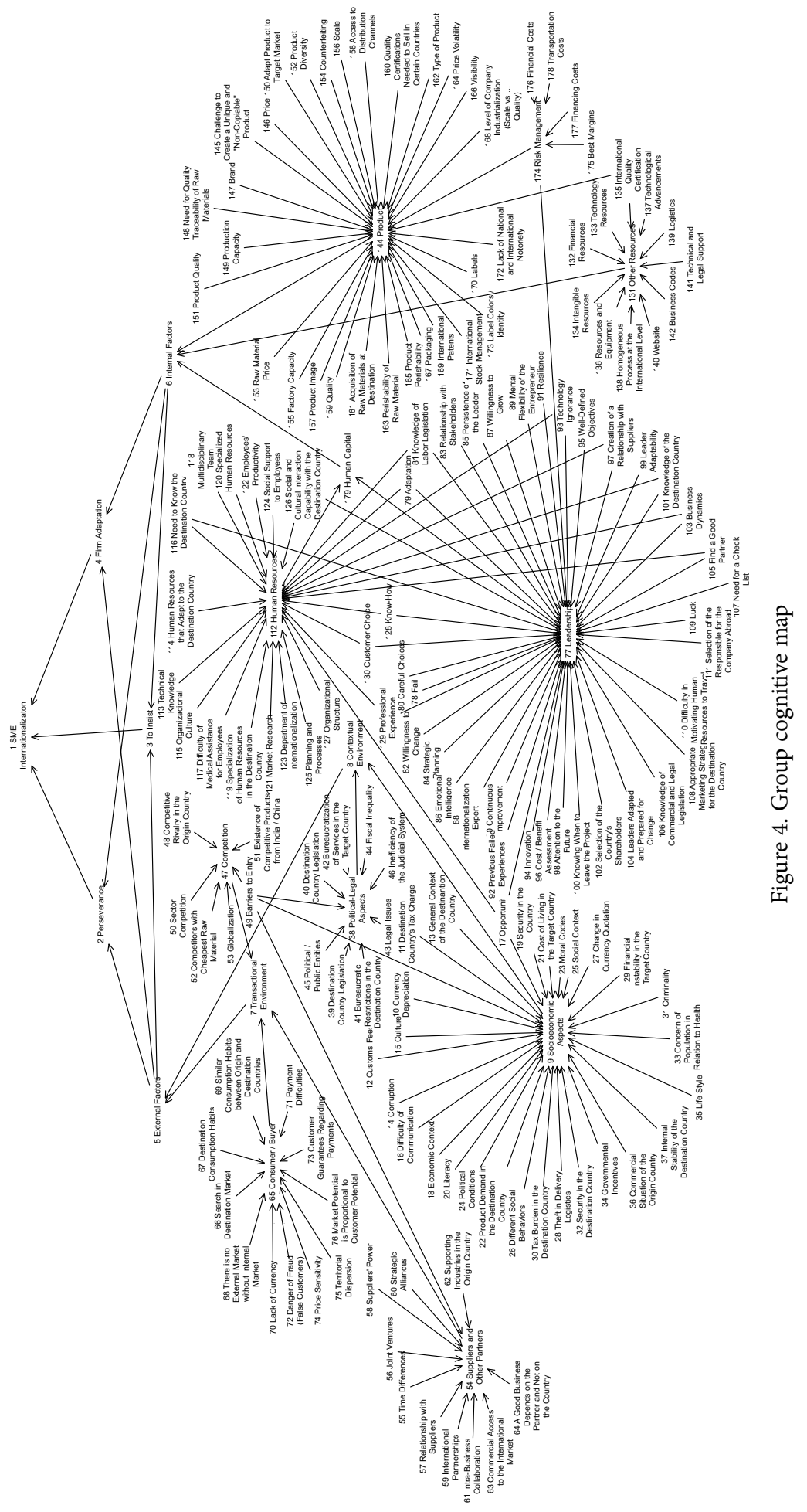




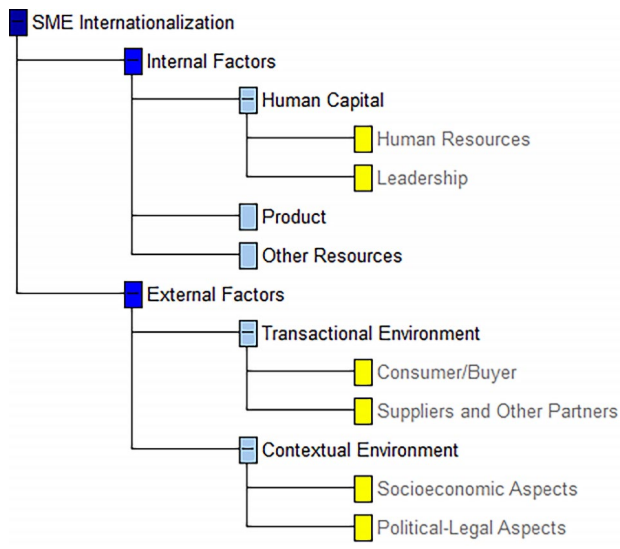

Figure 5. Tree of FPsV

External factors cover aspects external to SMEs that influence the firms and their people. These factors are represented in the tree by, first, the transactional environment, which includes external factors that directly influence the companies' activities. This environment comprises the consumer/buyer factor, which refers to the characteristics of the firms' potential customers (e.g., the danger of fraud and destinations' market demand and obstacles in the way of importing products). Another transactional environment factor is suppliers and other partners, which includes the suppliers' characteristics and their relationships with the SMEs (e.g., support industries in the home country, strategic alliances, and suppliers' power). The second external factor is the contextual environment, which covers the factors that influence the firms and employees' daily life. This environment is in turn represented by socioeconomic aspects that comprise the social and economic factors affecting the companies and their staff (e.g., currency fluctuation, corruption, crime, and security in the home country). Another contextual environment factor is political-legal aspects, which represents the bureaucratic and legal issues of the countries in which SMEs operate (e.g., inefficiencies in the judicial system, fiscal inequity, and destination countries' legislation).

With the value tree created and validated by the group, the decision process moved to the evaluation phase of the decision-making process, where evaluation scales and utility functions were defined. Partial evaluations of SME internationalization capability also were conducted.

\subsection{Evaluation phase: evaluation scales and decision rules}

The DEX method typically uses qualitative evaluation scales (Bohanec et al., 2013; Bohanec, 2014). Following the example of previous DEX-based studies (e.g., Ferreira et al., 2017c; Grillo et al., 2018), the scales used in the present study were defined based on the following four levels of performance: bad/unacceptable; acceptable; good; and excellent. This step was completed during the second group meeting. Figure 6 presents the qualitative scales the participants defined for each attribute in the value tree. 


\begin{tabular}{|c|c|}
\hline Attribute & Scale \\
\hline SME Internationalization & Unacceptable; Acceptable; Good; Excellent \\
\hline -Internal Factors & Bad; Acceptable; Good; Excellent \\
\hline -Human Capital & Bad; Acceptable; Good; Excellent \\
\hline Human Resources & Bad; Acceptable; Good; Excellent \\
\hline Leadership & Bad; Acceptable; Good; Excellent \\
\hline -Product & Bad; Acceptable; Good; Excellent \\
\hline -Other Resources & Bad; Acceptable; Good; Excellent \\
\hline External Factors & Bad; Acceptable; Good; Excellent \\
\hline -Transactional Environment & Bad; Acceptable; Good; Excellent \\
\hline -Consumer | Buyer & Bad; Acceptable; Good; Excellent \\
\hline LSuppliers and Other Partners & Bad; Acceptable; Good; Excellent \\
\hline Contextual Environment & Bad; Acceptable; Good; Excellent \\
\hline -Socioeconomic Aspects & Bad; Acceptable; Good; Excellent \\
\hline & :ellent \\
\hline
\end{tabular}

Figure 6. Evaluation scales

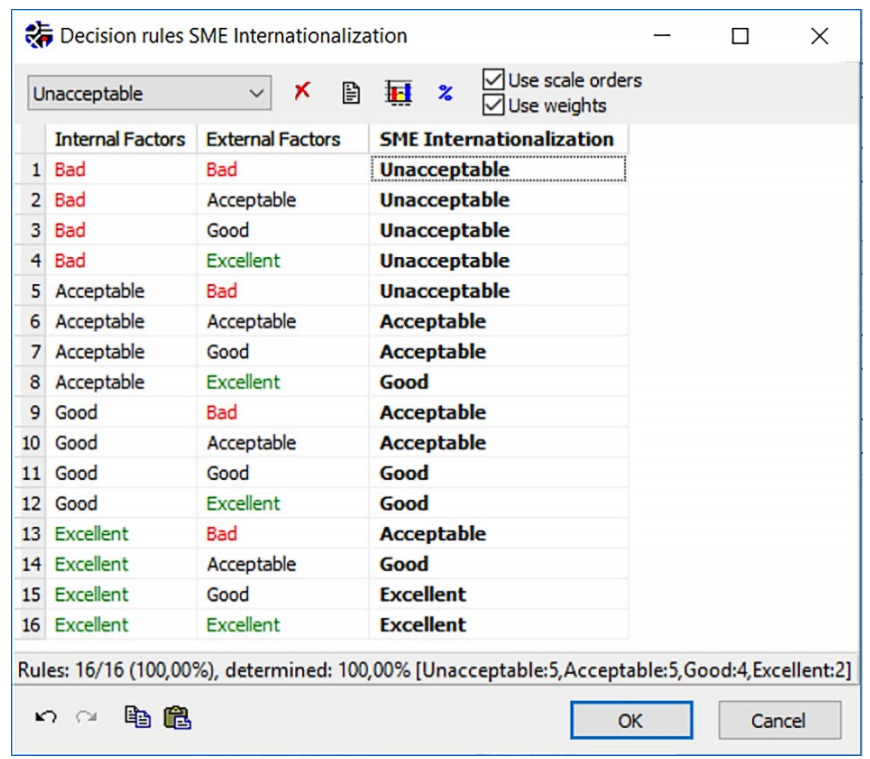

Figure 7. Utility function for SME internationalization capability

Next, the decision rules and utility functions were defined. Figure 7 shows the utility function created for assessing SME internationalization capability, which maps all possible combinations of internal and external factors. Because these factors had 4 possible scale values each, 16 decision rules were created (i.e., $4 \times 4=16$ ). In sequence, for each combination of internal and external factors (i.e., for each line), a decision rule was defined for evaluating SMEs' internationalization capabilities. For instance, line fifteen's rule reads:

$$
\begin{aligned}
& \text { If internal factors = excellent and external factors }=\text { good, } \\
& \text { then SME internationalization capability }=\text { excellent }
\end{aligned}
$$

The evaluation system created in this study has 6 aggregated attributes and, therefore, 6 utility functions. Figure 7 presents the first utility function. All other functions are available upon request. 
Bohanec (2014) argues that calculating trade-offs among decision criteria should not be a major concern when qualitative multi-attribute models are involved. However, weights were introduced into the present proposed framework to strengthen its potential for practical applications. Various MCDA methods and techniques could have been used to obtain the attributes' weights (for examples of different methods, see Belton and Stewart, 2002; Howick \& Ackermann, 2011; Zavadskas et al., 2014). In our study, the attributes' weights were defined by collective negotiation. Although this procedural step is nonlinear and inherently subjective, thus likely to be imprecise, the DEXi software facilitates interactive explorations of changes in inputs, thereby providing adequate support for the process of value estimation.

In addition, the process-oriented nature of the proposed evaluation framework needs to be emphasized primarily because this orientation makes the approach followed viable (for discussion, see Bell and Morse (2013) and Grillo et al. (2018)). Figure 8 presents the complex decision rules and attributes' weights applied in the present study. The next stage in this research consisted of using real data on local SMEs - henceforth called "Deltas" - to test the evaluation system created.

\subsection{Evaluating SME internationalization capability}

To test the evaluation framework, data on real SMEs were provided by the participants. Each SME was labeled as "Delta $i$ " with $i=\{1,2, \ldots, 5\}$. The evaluation of the Deltas' attributes is presented in Figure 9.

According to Figure 9, none of the Deltas was identified as excellent. Nonetheless, 3 of them reached a good level (i.e., Deltas 02, 03, and 05), and 2 were considered acceptable. Figure 10 shows the Deltas' overall evaluations.

The results presented in Figure 10 can be used to identify the SMEs with a good potential for successful internationalization initiatives. It is worth noting, however, that the evaluation mechanism developed in the present study is context dependent (i.e., the results depend on the context and participants involved in the research). Thus, extrapolations to other contexts without proper adjustment need to be avoided (see Ferreira et al. (2017c) and Grillo et al. (2018) for further discussion). In this end, a battery of "plus/minus 1" and dominance analyses were carried out to consolidate the results and verify the framework's internal consistency. Because these analyses can be used as a complementary tool in future discussions on internationalization processes, a file containing all the analyses is available upon request.

In the present study, "plus/minus 1 " and dominance analyses proved to be particularly useful as a way to promote additional collective discussion among the panel members, thus facilitating the formulation of recommendations that the Deltas may want to adopt.

On a technical level, "plus/minus 1" analyses reveal the variations that occur in response to changing performance figures in the attribute scale - both for lower $(-1)$ and higher $(+1)$ levels (Bohanec, 2014). As the example in Figure 11 shows, Delta 01 seems to be more sensitive to a single-level drop (i.e., -1). This type of analysis was carried out for all the Deltas.

The Deltas' partial performances were then analyzed and compared using scatter plots and radar charts, which allowed for further analysis of dominance results. Figure 12 shows the results for the transactional environment/contextual environment dominance analysis, which were obtained using DEXi software. 
Average weights

Attribute

SME Internationalization -Internal Factors Human Capital - Leadership Product

-Other Resources

xternal Factors

-Transactional Environment -Consumer | Buyer Suppliers and Other Partners Contextual Environment -Socioeconomic Aspects Political-Legal Aspects

Local Global Loc.norm. Glob.nom

$\begin{array}{rr}63 & 63 \\ 25 & 16 \\ 31 & 5 \\ 69 & 11 \\ 48 & 30 \\ 27 & 17 \\ 37 & 37 \\ 57 & 21 \\ 65 & 14 \\ 35 & 7 \\ 43 & 16 \\ 52 & 8 \\ 48 & 8\end{array}$

$\begin{array}{lr}63 & 63 \\ 25 & 16 \\ 31 & 5 \\ 69 & 11 \\ 48 & 30 \\ 27 & 17 \\ 37 & 37 \\ 57 & 21 \\ 65 & 14 \\ 35 & 7 \\ 43 & 16 \\ 52 & 8 \\ 48 & 8\end{array}$

\begin{tabular}{lll}
\multicolumn{1}{l}{ Internal Factors } & External Factors & SME Internationalization \\
\hline $63 \%$ & $37 \%$ & \\
\hline 1 Bad & $*$ & Unacceptable \\
$2<=$ Acceptable & Bad & Unacceptable \\
\hline 3 Acceptable & Acceptable:Good & Acceptable \\
4 Acceptable:Good & Acceptable & Acceptable \\
5 Good & $<=$ Acceptable & Acceptable \\
$6>=$ Good & Bad & Acceptable \\
\hline 7 Acceptable:Good Excellent & Good \\
8 Good & $>=$ Good & Good \\
9 Excellent & Acceptable & Good \\
\hline 10 Excellent & $>=$ Good & Excellent
\end{tabular}

Transactional Environment Contextual Environment External Factors

\begin{tabular}{lll}
\hline $57 \%$ & $43 \%$ & \\
\hline 1 Bad & $<=$ Good & Bad \\
$2<=$ Acceptable & Bad & Bad \\
\hline 3 Bad & Excellent & Acceptable \\
4 Acceptable & Acceptable:Good & Acceptable \\
$5>=$ Good & Bad & Acceptable \\
\hline 6 Acceptable:Good & Excellent & Good \\
7 Good & $>=$ Acceptable & Good \\
$8>=$ Good & Acceptable:Good & Good \\
\hline 9 Excellent & Excellent & Excellent \\
\hline
\end{tabular}

Human Resources Leadership Human Capital

\begin{tabular}{lll}
\hline $31 \%$ & $69 \%$ & \\
\hline $1<=$ Good & Bad & Bad \\
\hline 2 Bad & Acceptable:Good & Acceptable \\
$3<=$ Good & Acceptable & Acceptable \\
4 Excellent & Bad & Acceptable \\
\hline 5 <=Acceptable & Excellent & Good \\
6 Acceptable & $>=$ Good & Good \\
7 >=Acceptable & Good & Good \\
8 Excellent & Acceptable:Good Good \\
\hline $9>=$ Good & Excellent & Excellent \\
\hline
\end{tabular}

Human Capital Product Other Resources Intemal Factors

\begin{tabular}{|c|c|c|c|c|}
\hline \multirow{2}{*}{\multicolumn{2}{|c|}{$25 \%$}} & \multirow[b]{2}{*}{$48 \%$} & \\
\hline & & & $27 \%$ & \\
\hline 1 & $\mathrm{Bad}$ & $\mathrm{Bad}$ & * & $\mathrm{Bad}$ \\
\hline 2 & Bad & $<=$ Good & Bad & $\mathrm{Bad}$ \\
\hline 3 & & Bad & $<=$ Acceptable & $\mathrm{Bad}$ \\
\hline 4 & Bad & Acceptable:Good & Acceptable:Good & Acceptable \\
\hline 5 & $<=$ Acceptable & Acceptable & $>=$ Acceptable & Acceptable \\
\hline 6 & $<=$ Acceptable & Acceptable:Good & Acceptable & Acceptable \\
\hline 7 & $<=$ Good & Acceptable & Acceptable:Good & Acceptable \\
\hline 8 & $<=$ Acceptable & Excellent & $\mathrm{Bad}$ & Acceptable \\
\hline 9 & Acceptable & $<=$ Acceptable & $>=$ Good & Acceptable \\
\hline 10 & Acceptable:Good & <=Acceptable & Good & Acceptable \\
\hline 11 & $>=$ Acceptable & Bad & $\mathrm{s}=$ Good & Acceptable \\
\hline 12 & Acceptable & Acceptable & * & Acceptable \\
\hline 13 & Acceptable & Acceptable:Good & $<=$ Ac ceptable & Acceptable \\
\hline 14 & Acceptable & >=Acceptable & Bad & Acceptable \\
\hline 15 & Acceptable:Good & Acceptable & $<=$ Good & Acceptable \\
\hline 16 & Acceptable:Good & Acceptable:Good & Bad & Acceptable \\
\hline 17 & $>=$ Acceptable & Acceptable & $\mathrm{Bad}$ & Acceptable \\
\hline$\overline{18}$ & $<=$ Acceptable & $>=$ Good & Excellent & Good \\
\hline 19 & $<=$ Good & Good & Excellent & Good \\
\hline 20 & $<=$ Acceptable & Excellent & > =Acceptable & Good \\
\hline 21 & $<=$ Good & Excellent & Acceptable:Good & Good \\
\hline 22 & * & Excellent & Acceptable & Good \\
\hline 23 & Acceptable & $>=$ Good & $>=$ Good & Good \\
\hline 24 & Acceptable:Good & Good & $>=$ Good & Good \\
\hline 25 & Acceptable:Good & $>=$ Good & Good & Good \\
\hline 26 & $>=$ Acceptable & Good & Good & Good \\
\hline 27 & Good & Acceptable:Good & Excellent & Good \\
\hline 28 & >=Good & Acceptable & Excellent & Good \\
\hline 29 & Good & Good & $>=$ Ac ceptable & Good \\
\hline 30 & Good & $>=$ Good & Acceptable:Good & Good \\
\hline 31 & $>=$ Good & Good & Acceptable:Good & Good \\
\hline 32 & $>=$ Good & $>=$ Good & Acceptable & Good \\
\hline 33 & Good & Excellent & $<=$ Good & Good \\
\hline 34 & $>=$ Good & Excellent & $<=$ Ac ceptable & Good \\
\hline 35 & Excellent & Acceptable & >=Acceptable & Good \\
\hline 36 & Excellent & Acceptable:Good & Acceptable:Good & Good \\
\hline 37 & Excellent & >=Acceptable & Acceptable & Good \\
\hline 38 & Excellent & Good & $<=$ Good & Good \\
\hline 39 & Excellent & $>=$ Good & $<=$ Acceptable & Good \\
\hline 40 & $>=$ Good & Excellent & Excellent & Excellent \\
\hline 41 & Excellent & $>=$ Good & Excellent & Excellent \\
\hline 42 & Excellent & Excellent & > = Good & Excellent \\
\hline
\end{tabular}

Consumer | Buyer Suppliers and Other Partners Transactional Environment

\begin{tabular}{lll}
\hline \multicolumn{1}{c}{$65 \%$} & $35 \%$ & \\
\hline 1 Bad & $<=$ Good & Bad \\
$2<=$ Acceptable & Bad & Bad \\
\hline 3 Bad & Excellent & Acceptable \\
4 Acceptable & Acceptable:Good & Acceptable \\
5 Good & Bad & Acceptable \\
\hline 6 Acceptable:Good & Excellent & Good \\
7 Good & $>=$ Acceptable & Good \\
8 > Good & Acceptable & Good \\
9 Excellent & $<=$ Acceptable & Good \\
\hline 10 Excellent & $>=$ Good & Excellent \\
\hline
\end{tabular}

\begin{tabular}{lll}
\multicolumn{2}{l}{ Socioeconomic A spects } & Political_Legal Aspects \\
\hline $52 \%$ & $48 \%$ & \\
\hline 1 Bad & $<=$ Acceptextual Environment \\
$2<=$ Acceptable & Bad & Bad \\
\hline 3 Bad & $>=$ Good & Bad \\
$4<=$ Acceptable & Good & Acceptable \\
5 Acceptable & Acceptable:Good & Acceptable \\
$6>=$ Good & Bad & Acceptable \\
\hline 7 Acceptable & Excellent & Acceptable \\
8 Good & Acceptable:Good & Good \\
$9>=$ Good & Acceptable & Good \\
\hline $10>=$ Good & Excellent & Excellent \\
11 Excellent & $>=$ Good & Excellent \\
\hline & &
\end{tabular}

Figure 8. Complex decision rules and weights

Evaluation results

\begin{tabular}{|c|c|c|c|c|c|}
\hline Attribute & Delta 01 & Delta 02 & Delta 03 & Delta 04 & Delta 05 \\
\hline SME Internationalization & Acceptable & Good & Good & Acceptable & Good \\
\hline Hnternal Factors & Good & Good & Good & Acceptable & Good \\
\hline Human Capital & Acceptable & Good & Good & Good & Good \\
\hline Human Resources & Bad & Good & Good & Good & Good \\
\hline & Good & Good & Good & Good & Good \\
\hline oduct & Good & Good & Good & Acceptable & Excellent \\
\hline Resources & Good & Good & Good & Acceptable & Acceptable \\
\hline External Factors & Bad & Good & Good & Acceptable & Good \\
\hline -Transactional Environment & Acceptable & Good & Excellent & able & Good \\
\hline r|Buyer & Acceptable & Good & Excellent & Acceptable & Good \\
\hline -Suppliers and Other Partners & Acceptable & Good & Excellent & Acceptable & Good \\
\hline onteytul Fnvironment & Bad & Acceptable & Good & & Good \\
\hline cioeconomic Aspects & Bad & Acceptable & Good & Good & Good \\
\hline -Political-Legal Aspects & Bad & Acceptable & Good & Acceptable & Good \\
\hline
\end{tabular}

Figure 9. Deltas' evaluation (overall and each attribute) 


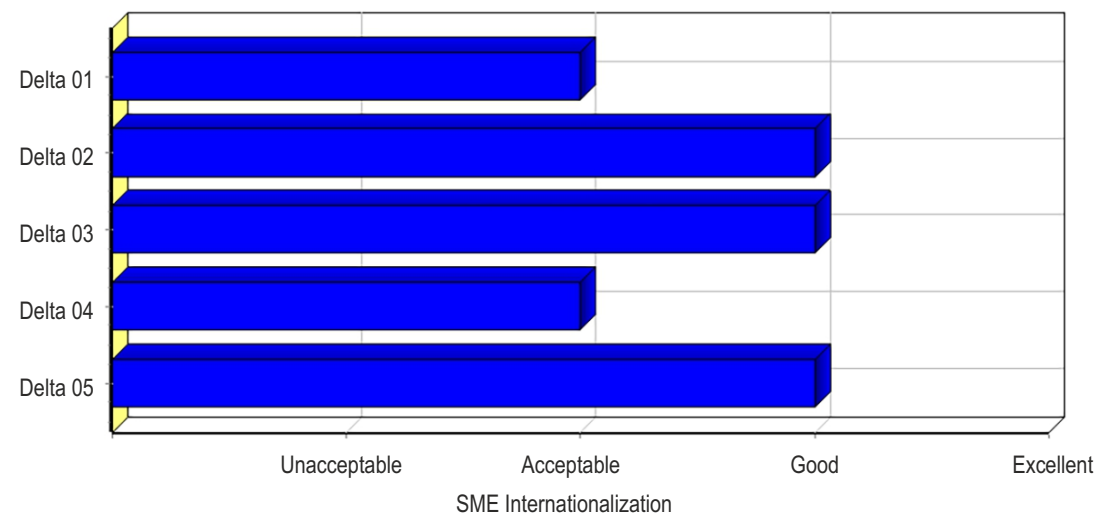

Figure 10. Deltas' overall evaluation levels

\begin{tabular}{ccl} 
Attribute & -1 & Delta 01 \\
\hline SME Internationalization & & Acceptable \\
-Internal Factors & & Good \\
\hline Human Capital & Acceptable \\
- Human Resources & Bad \\
Leadership & Good \\
Product & Unacceptable & Good \\
Other Resources & Unacceptable & Good \\
External Factors & Bad \\
-Transactional Environment & & Acceptable \\
- Consumer | Buyer & Acceptable \\
Suppliers and Other Partners & Acceptable \\
Contextual Environment & Bad \\
- Socioeconomic Aspects & Bad \\
Political-Legal Aspects & Bad \\
&
\end{tabular}

Figure 11. Delta 01's “plus/minus 1" analysis

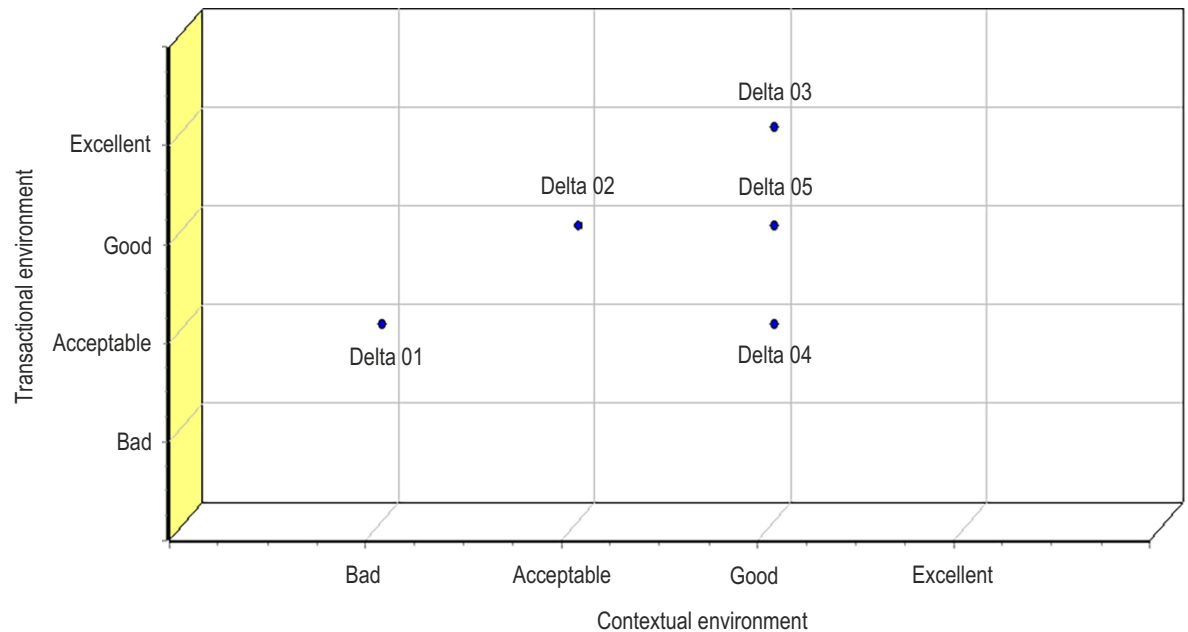

Figure 12. Scatter plots (transactional environment/contextual environment) 
As shown in Figure 12, scatter plots present the assessment results for two dimensions at a time, in this case, transactional environment and contextual environment. Delta 03 stands out as having a more favorable result against the other Deltas in terms of its transactional conditions, showing that this SME is the best in this particular dimension. Deltas 03, 04, and 05 received more favorable evaluations with respect to their contextual environment, highlighting that these SMEs present the most significant characteristics in this dimension. Due to the framework's constructivist stance, the evaluations carried out allow for the identification of which dimensions require improvement efforts. For example, Delta 04 still needs to improve in terms of its transactional environment even though this SME has one of the best performances regarding the contextual environment factor.

Radar charts, in turn, revealed which attributes should be improved for each SME analyzed. As the examples in Figure 13 show, Delta 01 clearly needs to improve its human capital, while Delta 04 should upgrade not only its products but also its other resources. Grillo et al. (2018, p. 711) assert that "this type of finding is an added value for the study since it [... seeks] to assist the selected SMEs to learn and thereby continuously improve through this evaluation process". Basically, the results reflect the epistemological stance adopted, which allowed the proposed framework to be treated as a learning mechanism rather than as a tool used alone to provide optimum solutions. This meant that a fuller understanding of SME internationalization capability could be achieved, thereby potentially offering support to decision makers in internationalization initiatives and processes.

Overall, the complementary analyses were extremely important as a way to go beyond a simple presentation of results and provide insights that support further reflection in future internationalization initiatives. Nonetheless, the idiosyncratic nature of the assessment mechanism created in our study should not be ignored. As discussed earlier, the results depend on the context and participants involved. This implies that proper adjustments need to be made before any extrapolation, generalization or implementation of the findings.
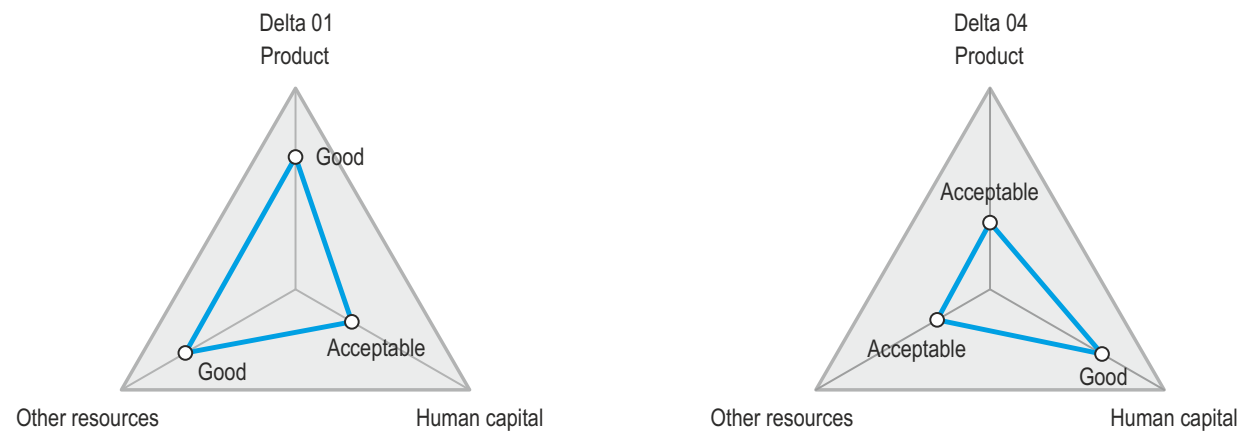

Figure 13. Examples of radar charts

\section{Conclusions}

In the current economic and technological landscape, SMEs' need for internationalization has intensified. As new technologies have emerged and globalization has spread, SMEs have faced increasing competition, which has forced them to look for external markets. Interna- 
tionalization processes, however, are expensive by nature, and SMEs typically have limited financial resources and poor internationalization skills, which often hamper their success in internationalization. In this context, new evaluation mechanisms are needed that can help SME decision makers make sound, informed decisions about internationalization issues. However, the studies carried out to date present limitations that restrict their application to real-life problems. Specifically, prior research show: (1) limitations on the methods used to identify evaluation criteria; (2) difficulties in the methods applied to calculate the tradeoffs of evaluation criteria; and (3) problems in analyses of the cause-and-effect relationships between criteria.

To address these limitations, the present study proposed using a combination of cognitive mapping and the DEX method to evaluate SMEs' internationalization capabilities. The model-building process was based on discussions and negotiations within a panel of SME entrepreneurs and CEOs, which allowed for the identification and articulation of the decision criteria included the evaluation framework created. The participants' overall satisfaction with the results allowed our SME internationalization assessment system to be validated, which was further consolidated by "plus/minus 1" and dominance analyses.

The findings include which attributes are of greatest significance in the assessment system. Internal factors $(63 \%)$ are more important to SME capability for internationalization than external factors (37\%) are. This result highlights that companies must consolidate and strengthen their internal resources before dealing with external factors, reinforcing a basic principle of resource-based theory. In addition, regarding internal factors, products are the organizational attribute with the highest weight (48\%) - almost as much as the remaining internal attributes' weights together. Based on this logic, products and their characteristics become the most important factors to evaluate in terms of SME internationalization capability.

While the results are encouraging, the proposed framework is both process-oriented and constructivist, so the proposed system should be used as a learning mechanism rather than as a stand-alone tool to prescribe ideal solutions. One of the framework's most important contributions could also be making subjectivity explicit and integrating it into quantitative data. Although context- and participant-dependent, the present results can serve as a starting point for other researchers seeking to identify and articulate the determinants of SMEs' internationalization capabilities, as well as a complementary component of ongoing and future studies.

In terms of further research, this study's findings could be reinforced by applying different MCDA techniques, which would facilitate the comparison of results. In addition, a well-focused evaluation system needs to be developed to assess SME internationalization capability in specific industries since each industry has specific characteristics that cause internationalization processes to be conducted differently. The resulting insights would strengthen the existing advances in the field of SME internationalization research.

\section{Acknowledgements}

This work was partially funded by the Portuguese Foundation for Science and Technology under Grant [number UID/GES/00315/2013]. Records from the expert panel meetings - including photographs, software output and the study's non-confidential information - can be 
obtained from the corresponding author upon request. The authors gratefully acknowledge the outstanding contribution and limitless willingness of the panel members: Ana Silva, Carlos Inácio, Gonçalo Pimpão, Ricardo Barroso, and Teresa Horgan. We also wish to thank the ISCTE Business School, University Institute of Lisbon, Portugal, for providing the necessary facilities.

\section{References}

Ackermann, F., \& Eden, C. (2001). SODA - Journey making and mapping in practice. In J. Rosenhead, \& J. Mingers (Eds.), Rational analysis for a problematic world revisited: problem structuring methods for complexity, uncertainty and conflict (pp. 43-60). John Wiley \& Sons.

Bana e Costa, C., Corrêa, E., De Corte, J., \& Vansnick, J. (2002). Facilitating bid evaluation in public call for tenders: A socio-technical approach. Omega, 30(3), 227-242. https://doi.org/10.1016/S0305-0483(02)00029-4

Barney, J. (1991). Firm resources and sustained competitive advantage. Journal of Management, 17(1), 99-120. https://doi.org/10.1177/014920639101700108

Bell, S., \& Morse, S. (2013). Groups and facilitators within problem structuring processes. Journal of the Operational Research Society, 64(7), 959-972. https://doi.org/10.1057/jors.2012.110

Belton, V., \& Stewart, T. (2002). Multiple criteria decision analysis: an integrated approach. Kluwer Academic Publishers. https://doi.org/10.1007/978-1-4615-1495-4

Bohanec, M. (1991). Introduction to DEX: an expert system to shell for a multi-attribute decision making. Jozef Stefan Institute, Ljubljana.

Bohanec, M. (2014). DEXi: program for multi-attribute decision making user's manual. Ljubljana University, Slovenia.

Bohanec, M., \& Rajkovič, V. (1990). DEX: An expert system shell for decision support. Sistemica, 1(1), $145-157$.

Bohanec, M., Cestnik, B., \& Rajkovič, V. (2001). Qualitative multi-attribute modeling and its application in housing. Journal of Decision Systems, 10(2), 175-193. https://doi.org/10.3166/jds.10.175-193

Bohanec, M., Rajkovič, V., Leskosek, B., \& Kapus, V. (2000b, July 9-11). Expert knowledge management for sports talent identification and advising process. In S. Carlsson, P. Brezillon, P. Humphreys, B. Lundberg, A. McCosh, \& V. Rajkovič (Eds.), Decision support through knowledge management, IFIP (pp. 46-59). KTH Royal Institute of Technology, Stockholm.

Bohanec, M., Rajkovič, V., Semolič, B., \& Pogačnik, A. (1995). Knowledge-based portfolio analysis for project evaluation. Information \& Management, 28(5), 293-302. https://doi.org/10.1016/0378-7206(94)00048-N

Bohanec, M., Rajkovic, V., Zupan, B., \& Bratko, I. (2013). DEX methodology: Three decades of qualitative multi-attribute modeling. Informatica, 37(1), 49-54.

Bohanec, M., Zupan, B., \& Rajkovič, V. (2000a). Applications of qualitative multi-attribute decision models in health care. International Journal of Medical Informatics, 58, 191-205. https://doi.org/10.1016/S1386-5056(00)00087-3

Calof, J., \& Beamish, P. (1995). Adapting to foreign markets: Explaining internationalization. International Business Review, 4(2), 115-131. https://doi.org/10.1016/0969-5931(95)00001-G

Carlucci, D., Ferreira, F., Schiuma, G., Jalali, M., \& António, N. (2018). A holistic conception of sustainable banking: Adding value with fuzzy cognitive mapping. Technological and Economic Development of Economy, 24(4), 1303-1322. https://doi.org/10.3846/20294913.2016.1266412 
Castela, B., Ferreira, F., Ferreira, J., \& Marques, C. (2018). Assessing the innovation capability of smalland medium-sized enterprises using a non-parametric and integrative approach. Management Decision, 56(6), 1365-1383. https://doi.org/10.1108/MD-02-2017-0156

Cerrato, D., Crosato, L., \& Depperu, D. (2016). Archetypes of SME internationalization: A configurational approach. International Business Review, 25(1), 286-295.

https://doi.org/10.1016/j.ibusrev.2015.05.010

Chandra, Y., Styles, C., \& Wilkinson, I. (2009). The recognition of first time international entrepreneurial opportunities: Evidence from firms in knowledge-based industries. International Marketing Review, 26(1), 30-61. https://doi.org/10.1108/02651330910933195

Child, J., \& Hsieh, L. (2014). Decision mode, information and network attachment in the internationalization of SMEs: A configurational and contingency analysis. Journal of World Business, 49(4), 598-610. https://doi.org/10.1016/j.jwb.2013.12.012

Çipi, A., Llaci, S., \& Ferreira, F. (2014a). A Delphi investigation into the corporate governance practices of Albanian joint stock companies. International Journal of Transitions \& Innovation Systems, 3(2), 88-103. https://doi.org/10.1504/IJTIS.2014.062809

Çipi, A., Llaci, S., \& Ferreira, F. (2014b). Corporate governance and the 2008 financial crisis: The Albanian experience based on the perception of joint stock company chief executive directors. Arethuse - Scientific Journal of Economics \& Business Management, 1/2, 49-70.

Correia, J., Ferreira, F., Meidute-Kavaliauskienè, I., Pereira, L. F., Zopounidis, C., \& Correia, R. (2020). Factors influencing urban investment attractiveness: an FCM-SD approach. International Journal of Strategic Property Management, 24(4), 237-250. https://doi.org/10.3846/ijspm.2020.12384

Czinkota, M., \& Ronkainen, I. (2012). International marketing. Thomson South-Western.

Dominguez, N., \& Mayrhofer, U. (2017). Internationalization stages of traditional SMEs: Increasing, decreasing and re-increasing commitment to foreign markets. International Business Review, 26(6), 1051-1063. https://doi.org/10.1016/j.ibusrev.2017.03.010

Dubravska, M., \& Sira, E. (2015). The analysis of the factors influencing the international trade of the Slovak Republic. Procedia Economics \& Finance, 23, 1210-1216. https://doi.org/10.1016/S2212-5671(15)00569-9

Dutot, V., Bergeron, F., \& Raymond, L. (2014). Information management for the internationalization of SMEs: An exploratory study based on a strategic alignment perspective. International Journal of Information Management, 34(5), 672-681. https://doi.org/10.1016/j.ijinfomgt.2014.06.006

Eden, C. (2004). Analyzing cognitive maps to help structure issues or problems. European Journal of Operational Research, 159(3), 673-686. https://doi.org/10.1016/S0377-2217(03)00431-4

Eden, C., \& Ackermann, F. (2001). SODA - The principles. In J. Rosenhead \& J. Mingers (Eds.), Rational analysis for a problematic world revisited: Problem structuring methods for complexity, uncertainty and conflict (pp. 21-41). John Wiley \& Sons.

Eden, C., \& Ackermann, F. (2004). Cognitive mapping expert views for policy analysis in the public sector. European Journal of Operational Research, 152(3), 615-630. https://doi.org/10.1016/S0377-2217(03)00061-4

Efstathiou, J., \& Rajkovič, V. (1979). Multiattribute decision making using a fuzzy heuristic approach. IEEE Transactions on Systems, Man, \& Cybernetics, 9(6), 326-333. https://doi.org/10.1109/TSMC.1979.4310221

European Commission. (2017a). Benefits of internationalization. Retrieved November 17, 2019, from https://ec.europa.eu/growth/smes/access-to-markets/internationalisation_en

European Commission. (2017b). SME performance review 2016/2017. Retrieved November 17, 2019, from https://blogs.ec.europa.eu/promotingenterprise/files/2017/11/SME-Assembly-2017-SMEPerformance-review.pdf 
Evers, N., \& O'Gorman, C. (2011). Network intermediaries in the internationalization of new firms in peripheral regions. International Marketing Review, 28(4), 340-364. https://doi.org/10.1108/02651331111149930

Ferreira, F. (2016). Are you pleased with your neighborhood? A fuzzy cognitive mapping-based approach for measuring residential neighborhood satisfaction in urban communities. International Journal of Strategic Property Management, 20(2), 130-141. https://doi.org/10.3846/1648715X.2015.1121169

Ferreira, F., Jalali, M., \& Ferreira, J. (2016). Experience-focused thinking and cognitive mapping in ethical banking practices: From practical intuition to theory. Journal of Business Research, 69(11), 4953-4958. https://doi.org/10.1016/j.jbusres.2016.04.058

Ferreira, F., Jalali, M., Bento, P., Marques, C., \& Ferreira, J. (2017a). Enhancing individual entrepreneurial orientation measurement using a metacognitive decision making-based framework. International Entrepreneurship \& Management Journal, 13(2), 327-346.

https://doi.org/10.1007/s11365-016-0388-5

Ferreira, F., Jalali, M., Zavadskas, E. K., \& Meidute-Kavaliauskiene, I. (2017b). Assessing payment instrument alternatives using cognitive mapping and the Choquet integral. Transformations in Business \& Economics, 16(2), 170-187.

Ferreira, F., Marques, C., Bento, P., Ferreira, J., \& Jalali, M. (2015). Operationalizing and measuring individual entrepreneurial orientation using cognitive mapping and MCDA techniques. Journal of Business Research, 68(12), 2691-2702. https://doi.org/10.1016/j.jbusres.2015.04.002

Ferreira, F., Spahr, R., Sunderman, M., Banaitis, A., \& Ferreira, J. (2017c). A learning-oriented decisionmaking process for real estate brokerage service evaluation. Service Business, 11(3), 453-474. https://doi.org/10.1007/s11628-016-0315-4

Filipe, M., Ferreira, F., \& Santos, S. (2015). A multiple criteria information system for pedagogical evaluation and professional development of teachers. Journal of the Operational Research Society, 66(11), 1769-1782. https://doi.org/10.1057/jors.2014.129

Foltin, C., \& Smith, M. (1994). Solve problems with software that captures and uses the knowledge of human experts: Accounting expert systems. The CPA Journal, 64(11), 46-53.

Gonçalves, J., Ferreira, F., Ferreira, J., \& Farinha, L. (2019). A multiple criteria group decision-making approach for the assessment of small and medium-sized enterprise competitiveness. Management Decision, 57(2), 480-500. https://doi.org/10.1108/MD-02-2018-0203

Goodwin, N., Harris, J., Nelson, J., Roach, B., \& Torras, M. (2014). Macroeconomics in context. Routledge. https://doi.org/10.4324/9781315702735

Greenbaum, S., Thakor, A., \& Boot, A. (2015). Contemporary financial intermediation. Elsevier. https://doi.org/10.1016/B978-0-12-405196-6.00022-7

Grillo, C., Ferreira, F., Marques, C., \& Ferreira, J. (2018). A knowledge-based innovation assessment system for small- and medium-sized enterprises: Adding value with cognitive mapping and MCDA. Journal of Knowledge Management, 22(3), 696-718. https://doi.org/10.1108/JKM-08-2017-0332

Hollender, L., Zapkau, F., \& Schwens, C. (2017). SME foreign market entry mode choice and foreign venture performance: The moderating effect of international experience and product adaptation. International Business Review, 26(2), 250-263. https://doi.org/10.1016/j.ibusrev.2016.07.003

Howick, S., \& Ackermann, F. (2011). Mixing OR methods in practice: Past, present and future directions. European Journal of Operational Research, 215(3), 503-511. https://doi.org/10.1016/j.ejor.2011.03.013

Jalali, M., Ferreira, F., Ferreira, J., \& Meidutė-Kavaliauskienė, I. (2016). Integrating metacognitive and psychometric decision making approaches for bank customer loyalty measurement. International Journal of Information Technology \& Decision Making, 15(4), 815-837. https://doi.org/10.1142/S0219622015500236 
Ju, X., Ferreira, F., \& Wang, M. (2020). Innovation, agile project management and firm performance in a public sector-dominated economy: Empirical evidence from high-tech small and medium-sized enterprises in China. Socio-Economic Planning Sciences, 72, 1-14.

https://doi.org/10.1016/j.seps.2019.100779

Keeney, R. (1992). Value-focused thinking: A path to creative decision making. Harvard University Press.

Kubíčková, L., Votoupalová, M., \& Toulová, M. (2014). Key motives for internationalization process of small and medium-sized enterprises. Procedia Economics \& Finance, 12, 319-328. https://doi.org/10.1016/S2212-5671(14)00351-7

Kunday, Ö., \& Sengüler, E. (2015). A study on factors affecting the internationalization process of small and medium enterprises. Procedia - Social \& Behavioral Sciences, 195, 972-981. https://doi.org/10.1016/j.sbspro.2015.06.363

Marques, S., Ferreira, F., Meidute-Kavaliauskienè, I., \& Banaitis, A. (2018). Classifying urban residential areas based on their exposure to crime: A constructivist approach. Sustainable Cities and Society, 39, 418-429. https://doi.org/10.1016/j.scs.2018.03.005

Mian, A., Rao, K., \& Sufi, A. (2013). Household balance sheets, consumption, and the economic slump. The Quarterly Journal of Economics, 128(4), 1687-1726. https:/doi.org/10.1093/qje/qjt020

Milici, A., Ferreira, F., Pereira, L., Carayannis, E., \& Ferreira, J. (2021). Dynamics of open innovation in small- and medium-sized enterprises: A metacognitive approach. IEEE Transactions on Engineering Management, 1-14. https://doi.org/10.1109/TEM.2020.3042458

Montibeller, G., \& Belton, V. (2006). Causal maps and the evaluation of decision options: A review. Journal of the Operational Research Society, 57(7), 779-791. https://doi.org/10.1057/palgrave.jors.2602214

Oliveira, M., Ferreira, F., Pérez-Bustamante Ilander, G., \& Jalali, M. (2017). Integrating cognitive mapping and MCDA for bankruptcy prediction in small- and medium-sized enterprises. Journal of the Operational Research Society, 68(9), 985-997.

https://doi.org/10.1057/s41274-016-0166-3

Oviatt, B., \& McDougall, P. (1994). Toward a theory of international new ventures. Journal of International Business Studies, 25(1), 45-64. https://doi.org/10.1057/palgrave.jibs.8490193

Oviatt, B., \& McDougall, P. (2005). Defining international entrepreneurship and modeling the speed of internationalization. Entrepreneurship Theory \& Practice, 29(5), 537-554. https://doi.org/10.1111/j.1540-6520.2005.00097.x

Pangarkar, N. (2008). Internationalization and performance of small and medium-sized enterprises. Journal of World Business, 43(4), 475-485. https://doi.org/10.1016/j.jwb.2007.11.009

Pérez-Bustamante Ilander, G., Marques, C., Jalali, M., \& Ferreira, F. (2016). The impact of continuous training in small and medium enterprises: Lessons from an industrial case analysis. Journal of Business Economics \& Management, 17(2), 234-250. https://doi.org/10.3846/16111699.2014.938359

Ribeiro, M., Ferreira, F., Jalali, M., \& Meidutè-Kavaliauskienè, I. (2017). A fuzzy knowledge-based framework for risk assessment of residential real estate investments. Technological and Economic Development of Economy, 23(1), 140-156. https://doi.org/10.3846/20294913.2016.1212742

Rita, D., Ferreira, F., Meidutè-Kavaliauskienè, I., Govindan, K., \& Ferreira, J. (2018). Proposal of a green index for small and medium-sized enterprises: A multiple criteria group decision-making approach. Journal of Cleaner Production, 196, 985-996. https://doi.org/10.1016/j.jclepro.2018.05.275

Simões, J., Ferreira, F., Peris-Ortiz, M., \& Ferreira, J. (2020). A cognition-driven framework for the evaluation of startups in the digital economy: Adding value with cognitive mapping and rule-based expert systems. Management Decision, 58(11), 2327-2347.

https://doi.org/10.1108/MD-09-2019-1253 
Surugiu, M., \& Surugiu, C. (2015). International trade, globalization and economic interdependence between European countries: Implications for businesses and marketing framework. Procedia Economics \& Finance, 32, 131-138. https://doi.org/10.1016/S2212-5671(15)01374-X

Trdin, N., \& Bohanec, M. (2012, May 25). Extending the multi criteria decision-making method DEX. In Proceedings of the 4th Jožef Stefan International Postgraduate School Students Conference (pp. 182-187). Slovenia.

Trdin, N., \& Bohanec, M. (2018). Extending the multi criteria decision-making method DEX with numeric attributes, value distributions and relational models. Central European Journal of Operations Research, 26(1), 1-41. https://doi.org/10.1007/s10100-017-0468-9

Welch, L. \& Luostarinen, R. (1988). Internationalization: Evolution of a concept. Journal of General Management, 14(2), 34-55. https://doi.org/10.1177/030630708801400203

Yener, M., Doğruoğlu, B., \& Ergun, S. (2014). Challenges of internationalization for SMEs and overcoming these challenges: A case study from Turkey. Procedia - Social \& Behavioral Sciences, 150, 2-11. https://doi.org/10.1016/j.sbspro.2014.09.002

Zavadskas, E. K., Turskis, Z., \& Kildienė, S. (2014). State of art surveys of overviews on MCDM/MADM methods. Technological and Economic Development of Economy, 20(1), 165-179.

https://doi.org/10.3846/20294913.2014.892037 